\title{
THE KASHMIRI SHAWL: RETHINKING PERSPECTIVES OF AUTHENTICITY AND APPROPRIATION IN POST-COLONIAL ERA
}

\author{
Bushra Jamil $1^{* *}$ and Umer Ismail ${ }^{2}$ \\ ${ }^{1}$ Pakistan Institute of Fashion and Design
}

\begin{abstract}
The twentieth century can be characterized by intensive cultural transfer and movement which followed two major modes; that of hybridity and consumption. Hybridity being best typified by the appropriations of non-European culture by the 60 s counter-culture movement, while consumption by a vibrant cultural tourism economy along with the objectification and commodification of hypostatized cultural products through the souvenir and exotica industry. These developments have created a rich material-visual culture and inventory of cultural expression which in the post-millennial era has brought the ideas of appropriation and authenticity to the forefront of public and intellectual discourse. This study uses the case of the Kashmiri shawl to critique and analyse current ideas of cultural authenticity and appropriation in view of building a theoretical framework that charts out these cultural processes along three axes; cultural zones (horizontal), historical progression (lateral) and social stratification (vertical). This axial perspective aims to create a conceptual model for mapping cultural landscapes that carries the combined theorizing and analytical potential lacking in current models for understanding cultural transfer: a) a model for theorizing ideas like appropriation clearly through an independent structural model of culture; b) a nuanced model that maps out cultural landscape along three dimensions of cultural movement; c) a global model that consolidates different cultural terrains into one interconnected whole.
\end{abstract}

Keywords: appropriations; authenticity; hybridity; post-colonialism; culture

\section{Introduction}

\section{The Rationale}

Marxists have long argued that our relationship to our environment can inevitably only mimic our social relations and the dominant ideas in relation to capital in the current stage of historical development. The aggressive defense of intellectual property rights in the global North, the emergence of cultural studies as a frontier for post-colonial discourse in the academia and the popularization of the ideas of cultural appropriation in public and academic discourse - all three developments do lend credence to the Marxist idea that can be summarised as below:

- Culture can be owned

- It is a form of capital thus subject to similar laws

- Our struggle for our share of other forms of capital and power is not independent of our rights in relation to cultural capital.

The process of objectification, commodification, and fetishisation, consequently is carried out by institutions and individuals. This has evidently helped expansion of cultures into globalized whole, democratised education and cultural activity and protected the economic and intellectual rights of weaker social agents. Yet, like all perspectives born out of specific historical conditions, political dissidence and confrontation, our current ideas 
regarding cultural appropriation and authenticity are riddled with contradictions, exaggeration and poor reasoning and evidence.

Though the basic and overarching question whether culture can be owned, is beyond the scope of this paper, the current study aims to challenge the dominant and mainstream perspective and posit that these perspectives are arbitrary, hither to absolute in their instrumental value and to some extent destructive as far as social political harmony and cultural evolution is concerned. Thus due to the last assertion, the question and task that this study focuses on tilts more towards whether culture should be owned, rather that if it can be owned. The researcher has chosen the Kashmiri shawl, due to its fulfilling objectives of the study on the following contents:

- It belongs to a region which came under direct and intensive colonial influence and activity.

- It has a life spanning pre-colonial, colonial and post - colonial contemporary era.

- Its extraordinary assimilation into European culture and the active European influence in its growth.

The paper then proceeds to remedy the current theoretical poverty in regards to the idea of appropriation and authenticity by building a conceptual framework which concerns primarily with understanding the cultural landscape with a multi-dimensional realism, while arguing alongside that

- The map is not the territory

- Theory can only strive for advances in balancing realism, efficacy (political, social) and instrumental pragmatism and theoretical imagination.

In short, an open source theory that is Humanities- centric while being as empirically justified and malleable as possible.

The Kashmiri shawl poses an interesting case study for our current understanding and perspective of cultural appropriation and authenticity of cultural forms. Firstly, due to its extraordinary longevity (five centuries) as a craft and cultural phenomena. Secondly due to its constant evolution, diversification through time and across its cultural and geographic regions. Thirdly for it being perhaps the only example from material culture and textiles in particular which achieved total appropriation from colonies to the imperial centre. While exhibits of cultural transfer outwards from centre towards the colonies are ample- cricket and tea being best examples in the subcontinental context- cultural movement in the reverse direction from colonies to the centre tells a different story in which the Kashmiri shawl holds a unique and unparalleled status. Contemporary study of orientalism is made with reference to Edward Said;

"It is, above all, a discourse that ... is produced and exists in an uneven exchange with various kinds of power ... it is, rather than expresses, a certain will or intention to understand, in some cases to control, manipulate, even appropriate what is a manifestly different ... world.” (Said, 1978)

It went from being an exotic orientalism and fashion statement to a cultural object that came to define Britishness, create a space for itself within convention and acquire ceremonial function of a conservative nature and in the case of France succeeded in creating a hybridity that later became one of the landmarks of French aesthetics and taste. Fourthly for being the only cultural object that was subject to consistent, intensive, semi successful attempts at imitation, in state and private enterprise. Lastly due to its cosmopolitanization as a cultural object and a trope in consumer consciousness and popular culture with an enduring legacy in modern design vocabulary through the boteh or paisley motif.

\section{Authenticity and Appropriation}

In general authenticity is a concern for verification that a work is genuine and reflects an artistic tradition. In terms of material culture it refers to original form of an object including its technique, material, and unique 
features. According to Lawless and Silva (2015a; 2017) authenticity is understood as an objective and measurable attribute that is inherent in product. It is linked to psychological process of truth seeking (Kreuzbaur $\&$ Keller, 2017). Appropriation on the other hand is seen as adoption of cultural practices, symbols or ideas of a culture or society by members of another and typically more dominant society. The idea of authenticity carries considerable significance in the context of the Kashmiri shawl encounter with European appropriations. Historically, Kashmiri shawl and its various varieties such as Pashmina, Kani and Shahtoosh were highly valued and precious possession, passed on through generations and a symbol of status and nobility mostly owned by the royalty and elite. European colonists in Indian subcontinent perceived Kashmiri shawl through this lens. Modernity and industrialization of the Indian craft economy and globalization of cultural forms and their subsequent commodification and exploitation by late capitalism also influenced the process of appropriation. While postcolonial theory, literature and socio-political consciousness has pushed ideas such as cultural appropriation, cultural imperialism and authenticity to the forefront of the global discourse on the socio-cultural landscape, our general understanding of the idea of authenticity and appropriation remain unstructured, ambiguous and insufficiently developed theoretically. This section attempts to justify the preceding evaluation, proposing a basic a theoretical framework for understanding cultural movement.

Cultural appropriation and authenticity is significant because in effect it ends up also dealing with foundational and central ideas such as unit, the porosity and boundaries of culture, cultural movement in a postcolonial context and through a postcolonial lens, cultural cohesion and diversification. Most of all the relationship between past and present. If appropriation is both a process and concept, authenticity an evaluative tool and concept, then they must operate within the larger apparatus of a theoretical framework with both influencing and defining each other. It is primarily this conceptual mechanic that our inquiry sets out to explore.

\section{Demarcation of Cultural zones- some anomalies}

In the context of textiles, appropriation can be defined as the movement of material culture across geographical and/or cultural zones. For this definition to be theoretically or analytically operational we must have some understanding of cultural demarcations; i.e. how do we define a cultural and geographic zone? An article of a culture moves into another; this statement is meaningless in terms of discourse if we do not have some way of encircling the two cultures. In other words how can we speak of what is being appropriated without an understanding of what qualifies an object to belong to a particular culture and how do we define the boundaries of that culture?

If the whole world at any given moment in history can be seen as an expansive, variegated and interconnected cultural landscape along a spatial axis, how do we define this whole into cultural units or categories? What is the rationale of cohesion and differentiation through which we can dismantle a large cultural region into smaller cultural categories, for example Indian culture $\rightarrow$ Kashmiri culture and Punjabi culture and similarly integrate smaller cultural zones into a megalith cultural category, like Kashmiri culture $\rightarrow$ Indian culture. The manner in which we carry out this labelling of the cultural landscape or categorization, it influences our understanding and particular application of the ideas of appropriation and authenticity. It also shapes our ideas of cultural identity and our place in them.

To consider the case of the Kashmiri shawl, the discourse on its appropriation into colonial Europe takes for its analytical premise the whole episode to be an example of Indian culture being appropriated by a foreign colonizing cultural entity i.e. Britain and/or France. The discourse on the Kashmiri shawl's appropriation is from a critical position on colonialism and uses a Saidian reading of Orientalism as a base concept, they treat the vast cultural landscape of the subcontinent as one cultural unit that is Indian culture. This raises the question that if it is origins which determine authenticity which in turn define the modalities of appropriation, than doesn't the Kashmiri shawl belong to Kashmiri culture, rather than the megalith category of Indian culture. Secondly identifying the Kashmiri shawl as an item within the broader fictional set labelled Indian culture skips a 
genealogical step in the cultural history of the Kashmiri shawl and is an act of appropriation in itself. The fact that the Kashmiri shawl was itself appropriated into the imperial culture of the Indian mainland by early Mughal emperors is not seen to qualify as appropriation or at least not significant enough to be considered alongside its European appropriation.

The exact nature of these two appropriations are different yet it cannot be dismissed that there is no understandable reason for not viewing the movement of the shawl as a material culture from Srinagar to Delhi as appropriation just as its movement from Lahore and Delhi to London and Paris is unarguably an act of appropriation. Neither does the difference in nature of these appropriations necessarily dictate that one is more important than the other. Although these apparent application of appropriation as a theoretical construct seem incredibly irrational and incoherent under closer scrutiny as exemplified above, they are made possible through a conscious rationale and perspective, which brings us to our original point.

Table 1:Axel Structure

\begin{tabular}{|l|l|l|l|l|}
\hline Axes & Plane & $\begin{array}{l}\text { Referent Boundaries/ } \\
\text { Space }\end{array}$ & Points & Example \\
\hline Horizontal & Spatial & Cultural/ Geographical & Zone & Indo-Persia/Germany/ Naples \\
\hline Vertical & Hierarchal & Social Strata/ Class & Tier & $\begin{array}{l}\text { Mercantile-Shia Kashmiri-Pundit/ } \\
\text { Aristocracy Catholic Bavarian }\end{array}$ \\
\hline Lateral & Temporal & Historical & Node & $\begin{array}{l}\text { Post-partition/ Communist era/ } \\
\text { early Renaissance/ Millennial }\end{array}$ \\
\hline
\end{tabular}

\section{What is ours?}

The idea of cultural categories and cultural zones along the spatial axis will determine what instances of cultural movement we consider to be appropriations. This point is further substantiated by the occurrence of even a few parallels between the European and Indian appropriation of the Kashmiri shawl. Just like European efforts towards appropriating the Kashmiri shawl industrially, the Mughals rulers made attempts to appropriate the shawl by attempting to replicate the Kashmiri shawl through setting up workshops and entire weaver's community nearer to imperial centres like Delhi, Bengal and Lahore. Interestingly enough just like the Europeans they only partially succeeded in an industrial appropriation along the lines of replication. "The demand for Indian shawls made it opportune for British manufacturers to mass produce imitation shawls." (Choudhury, 2015). If what differentiates the European case from the Mainland Indian, is that the European is characterized by imperialist-dominative-exploitative-oppressive- (IDEO), what we understand to be the sharp edge of colonialism, then are we certain that Mainland India's (Mughal, Sultanate, Sikh) are not characterized by IDEO? A dispassionate and objective study of pre-Colonial history of Kashmiri offers much to the contrary. Two potent examples that provide windows to new perspectives:

The royal atelier or karkhana industry founded by Turkic-Persian rulers made wide use of slavery and forced labour (Muhammad Shah in the $13^{\text {th }}$ century turned 12,000 slaves into artisans to found one of the first textile ateliers to produce silks and brocades for the royal toshakhana). The pashmina and shahtus industry in Sri Nagar that the Mughals inherited after their conquest of Kashmir, differed negligibly from those baseline conditions apart from slavery, replaced with a weaver class that literally wove to not starve. A common Kashmiri idiom that served as curse that women offered to each other ran: May you marry a weaver. The best period for artisans and ruled territories in pre-Colonial India is widely considered to be the Mughal, especially Akbar onwards, who is also regarded as the spiritual super-patron of the Kashmiri shawl. 
"The lower class consisted of cultivators, artisans, small traders, slaves, shopkeepers, etc. They led a hard and unattractive life. Their life was simple and their belongings were limited." (Anon., 2011)

Yet, the socio-economic conditions and labour opportunities of weavers in Sri Nagar were worse under him than in any period of direct or indirect European rule of Kashmir.

"The Dogra rulers would eat into the hard toil of artisans especially the shawl weavers by imposing heavy taxes on their products. The horrible tales of exploitation of Kashmiri people motivated people.........to visit Kashmir and find out truths about starvation deaths......... They perceived that among the gravest problems of the people of Kashmir, (both rural and urban) was that of poverty." (Khaja, 2016)

The Kashmiri shawl industry and economy under the Mughals served no other group, class or sociological purpose other than the creation of cultural and economic capital for the Mughal house. This was not a social or public economy, it was a state economy that was privately owned. Ironically enough, a recurring element in the case against European colonialism is precisely in the same vein; that the industrial and cultural wealth created by colonial enterprises was created for colonists and only served the colonists, with the residual benefit to the colonized population being necessary for perpetuating colonial rule. This is just as true of the Kashmiri shawl industry of Sri Nagar in Mughal times.

The purpose of the above comparison is not a social evaluation of Mughal and European rule in India, but is in fact to reconsider, open up new theoretical space for the analysis of cultural movement, heritage and appropriation. An honest and objective study of the shawl's history and discussions on its appropriation does cast doubt on our overwhelmingly Euro-centric definition of colonialism.

This puts our original question in a more concrete context - how do we determine what is ours? Does the Kashmiri shawl still belong to the megalith category we referred to as Indian culture when it once was a native craft of the small and relatively insulated mountain state, whose original patrons and creators neither strived nor held any assimilationist or expansionist ambitions for their material culture of which the Kashmiri shawl was a part? If rights to appropriation our validated by the host cultures positive contribution to the resource culture object of interest than the simplistic criticism of European appropriations are easily contestable, since there are several aspects and examples of the European encounter with the shawl that are far from being inherently malevolent or exploited. Similarly from whose perspective can we determine what qualifies as a positive contribution from the resource culture? In other words if what is ours is loosely determined by what we have helped create. Than most demarcations of cultural achievements (intellectual or material) appear to be painfully arbitrary, ambiguous and to some extent crudely fabricated. The overwhelming evidence from human cultural history points in the direction of dialogue, integration, synthesis, syncretism, and a general theme of cultural permeability and interventionism. Very few landmarks of material culture can be considered to have arisen and evolved in a monoculture closed system and through methods free of violence, inequality or IDEO. It is from this idea of cohesion that formulates a culture's understanding of what its boundaries are, how other cultures identify and relate to each other and biases regarding appropriation and authenticity. Globalization has resulted in the dissolution of older cultural barriers and together with the eclecticism and hybridity of postmodern cultural developments.

\section{Where is the Past?}

Our ideas of authenticity and appropriation are also deeply connected to our understanding of cultures through time and not just across space. While in the previous section we carried out a discussion regarding the demarcation of cultures and the trend towards their consolidation of cultural spaces into megalith. In this section I will look at the same question but along the axis of time rather than cultural or geographical space. It is 
thought-provoking idea the love of one city is not just a longing for a native space but also a particular time which made that city a different space from what it might be today, this carries profound understanding of time, space and cultural landscape: the past is not just a different time, it is a different space. When you or I speak of ourselves as belonging to a culture that statement is made meaningful because it has provided locus of a horizontal axis of space which differentiates it from other cultures on it, that process of contextualizing, identification and differentiating is more complex if we rotate the axis under analysis and view cultural landscapes through time. The discourse of appropriation and authenticity treats the movement of material culture across time simplistically to the point of it not being relevant as an example of cultural movement. Our idea of what is ours across time is just as problematic and open to interpretation. The overwhelming trend in the discourse on appropriation embodies a singular fixation with cultural movement across spatial boundaries in particular with non-European cultural forms being appropriated. The trend in Europe regarding the Kashmiri shawl appropriation and public opinion together point to a locomotive understanding of cultural lineage and authenticity. This means that; members of cultures are seen to be passengers on a train that is their cultural identification with all previous eras and their contents. The given heritage of the passengers like compartments in a train. The present is indeed made up of the past and we are its mental heirs, hence this understanding is not problematic. However it is when this locomotive understanding of one's culture enters the domain of value judgments, prescriptive analysis, ethics of cultural conduct-basically any essentialist reading- that the problematic and incoherent nature of this leaner understanding of cultural identification begins to show its hands and exhort narrative influence. Let us explore the conceptual and practical repercussions of this.

Firstly if for the sake of argument and analysis we take up a megalith like Indian culture as a cultural identification category it does not necessarily follow (and inevitably cannot) that two cultural situations separated by time within the same perceived cultural identification category should be regarded as the same culture; this is paramount to stating that the Delhi or Lahore of 1618 belongs to the same culture as the Delhi or Lahore of 2018; to refer to both cultural situations as Indian culture tells us less than it conceals and confuses. While the latter could be seen as the progression of the former (even though they cannot be reduced to just that), it is not necessarily a continuation of the former. To view them as mere points on a sliding scale of one cultural corollary ignores the qualitative potential of cultural evolution and the capacity (if not as an inevitable tendency) to reinvent themselves and to be disrupted and influenced from the outside to the point of becoming differentiated enough to be considered a different culture altogether. This is especially true in postcolonial cultural situation. To say that something from our culture is appropriated into another culture, we are also saying: this is not yours, be careful, since you are accountable for how you appropriate it! Yet, through what logical or cultural law do we take for granted that the object being appropriated is ours to begin with? This understanding of appropriation is built upon more than a few presumptions that merit examination and critique.

The first is the idea of culture being an essentially locomotive phenomena moving along a temporal axis, and while it might be in the context of tribal societies that remain relatively unchanged and exist outside modernity, it cannot be our standard understanding of cultures today in a postcolonial context. If we do dislodge this presumptive popular notion of culture being a locomotive reality and the present of a cultural identification category being essentially a continuation of its past, our own identification, relationship with, and ownership of the past becomes less obvious and worthy of re-evaluation and is cast in serious doubt. Therefore when one culture says to another you have appropriated something of my culture, something that I own since my present cultural situation is a continuation of the past cultural situation where the origins of the respective object of appropriation are situated, it may be possibly forgetting that it itself is appropriating that very cultural object from what it considers its past, of which the present may not be necessarily a continuation. In a post-colonial context this locomotive logic of ownership and its subsequent idea of appropriation is incoherent, confused and somewhat contradictory. If we are to pin down cultural situations on the temporal axis through the use of cultural identification categories or megaliths we need to first establish a rationale of cohesion that strings together different cultural situations on the same axis of time. In other words, discover profound underlying or overarching connection(s) that run through different cultural situations on the same axis of time. The present 
analysis does not deny the existence of such connections obviously, it merely suggests that two cultural situations separated by considerable time on the same axis of time can and in some cases should be considered different cultures all together (especially in postmodern contexts). To view them through a prism of cultural identification categories (e.g. Indian culture) that are fixed or a locomotive whole along the temporal axis is problematic. In the context of material culture, this consideration is even more significant as the potential of alienation between material objects and their cultural logic or their role as signifiers (parole) to an ever-evolving signified (langue) is greater and more pronounced due to the phenomenological distance between the material and the abstract, the latter being what culture essentially is.

Susan Pearce adopts Saussure's ideas of langue and parole to the reading of material culture, arguing that the meaning of objects like language is born through the relationship between:

- Society's or culture's material vocabulary or possibilities and the rules through which this vocabulary will be used to express meaning (langue);

- The concrete embodiments of langue through a specific action or object that make up and alter social reality and allow communication in actual everyday life (parole);

- The subjective micro context which the individual observers perceptions places on it. The subjective and symbolic meaning that an individual or group places on it (what we will call narration/ the personalized version of Barthe's signe).

"The perceptions which matched the aspirations of the class in power naturally tended to suppress or dislodge those which were officially regarded as more subversive and it is these perceptions which ultimately brought the jacket into its museum collection” (M.Pearce, 1994)

The above citation is taken from Susan Pearce's text, Narrating the Past in which among other things, she shows us the polysemantic nature of objects from the past through the example of a much-famed military jacket from the battle of Waterloo now curated at the National History Museum. Her analysis sheds light on how an object of the past can be interpreted in different and at times categorically or thematically opposite ways. The passage above is a broad explanation by Pearce for how a particular interpretation or what we can call an interpretation set comes to be chosen over other possible interpretations, narratives and themes; class dynamics. These themes may have their locus in what is our understanding of the past, i.e. how different groups/ cultures /individuals did or would have interpreted the object in its own present, and similarly may have their locus in the present, i.e. how different groups/cultures/individuals interpret the object today and the perspectives that can be applied to it. For example, the Waterloo jacket would have been (and is today) a symbol of national pride, bravery and victory as its socially normative theme consistent with the dominant ideology, yet a significant majority of the lower classes of Britain who identified and sympathized with Napoleon and the ideals of the French revolution viewed the battle of Waterloo in tragic terms as a defeat of revolutionary forces and the role of British soldiers as accomplices to the oppressive class- how radically different would their associations with Waterloo jacket be from the official theme? Especially when the British victory at Waterloo resulted in a fiercely violent crackdown on revolutionaries at home?

The above is a case in point for the degree of variation in the possible symbolic associations an object can carry in its own present (or what for us is the past). Put simply, an object can have very different meanings for people that exist in the same time, society, cultural and geographic zone (or what can be termed a cultural situation). As exemplified above, variation in themes and narratives within the same cultural situation is at times most pronounced along the lines of class structure and political ideology $y^{i}$ This is the third axis of our theoretical structure and it is the vertical axis of hierarchical order that is a society or culture's social stratification at any given time. Having carried out discussion and analysis framed along the temporal axis and the spatial axis, now we shall try to understand the Kashmiri shawl along the hierarchical axis. Let us consolidate this insight 
conceptually into the axial framework we have discussed and built so far, after which we can apply it to the Kashmiri shawl.

\section{Made for the Rich and Told by the Rich}

The Kashmiri shawl as an object from material culture has been approached through the lens of its consumers, connoisseurs and patrons. We can chart out a vector of sources from Mughal times to our current contemporary scholarship and see a patterned discourse of overwhelmingly upper tier or aristocratic perspective and appreciation. What do we exactly mean by this? Firstly, it is the social modality of the discourse, having a primary interest in exploring the relationship of the Kashmiri shawl to its privileged consumers and patrons, its influence on their socio-cultural and political existence and vice versa and its aesthetic readings as a piece of material culture. We can call this a modal perspective. In this case, the mode of consumption binding the pattern of discourse. In particular one that issues forth from the consumer-patron class tiers and lands its gaze on the commodity side of the Kashmiri shawl which is its hierarchically opaque face, this is the Kashmiri shawl's objectification which turns it into what Bourdieu terms cultural capital "Pashmina has enraptured Westerners, with European royalty and wealthy women including these shawls as an essential part of their wardrobes." (SINGER, 1999). Consequently, this objectification also reifies into the object symbolic capital allowing it to function as a class signifier or social marker. As expressed earlier, if there is one semiotic characteristic of the Kashmiri shawl that runs through its varied existence on the horizontal and lateral cultural axes, it is class fetish. Understanding this symbolic capital and the fetish character of the Kashmiri shawl also sheds light on the present context of the shawl. An object can be understood in its socio-economic context, or along the lines of the means of production, as having two faces to it. One being the commodity end and the other being its social end. The first is primarily a view of the thing as an object, a finished product that defines the material culture and gives meaning to social activity of the tier that consume and/or produce it (considering the case where the consumer, producer and patrons belong to the same broader class category). This face which we can call the hard-face or the thing-as-object is opaque in varying degrees to the product/object's relationship to wider society, the social relations of its production and its overall social and ecological cost, all of which can be called the back-face or social end which does not view the object as a finished product or object but rather as a process, phenomenon and activity, or the thing-as-agency. Not until the post structural readings of the late 70 s/80s do we find even a semblance of a perspective that views the Indian craft economy and culture from its back-face and socio-ecological end, or offers a balanced understanding of material culture that is not fixed in the mode of consumption. Yet these scattered and specialized studies- of which Susanne Daly, Chitralekha Zutshi and Michelle Maskiel are good examples- are not enough to form an actual perspective, coherent narrative or indepth understanding of the shawl as a socio-economic reality. Most of all they are all euro-centric and fixate their attention on Victorian Britain's encounter of the Kashmiri shawl. Similarly, out of the four works that are considered the standard in scholarship on the Kashmiri shawl John Irwin, Frank Ames, Janet Rizvi, and Nahid Jaffery and Sherry Rehman only the latest one, namely Jaffery \& Rehman, offers a glimpse into the lives of the working classes and larger society in relation to the Kashmiri shawl. This however, is also a merely descriptive and historical treatment. The Kashmiri in public discourse and popular imagination is similarly an overwhelmingly hard-face view which consequently views the Kashmiri shawl as purely a piece of objectified cultural capital.

Yet, until the mid- $20^{\text {th }}$ century, the production of the shawl, its system of commerce and social relations it forms and perpetuated are a stark example of class warfare, exploitation and at times labour arrangements that differ only slightly from slavery and indentured labour. If we recall the somewhat concise portrayal of the Kashmiri shawl back face well into the early $20^{\text {th }}$ century we begin to see clearly what Jaffery calls the "human face of the shawl.” (Sherry Rehman, 2006)

Returning to the point of class dynamic determining the social modality of discourse on material culture and its viewings, if we take Pearce's framework for analysis and apply it to the Kashmiri shawl, the questions and 
observations that arise from it are profound and show us the possible one-dimensionality of heritage and material culture discourse, especially crafts that are considered to be high culture of the colonies. We already have a sense of the modality of discourse prevalent in the majority of academic inquiry and similarly the public narratives and popular imagination regarding the Kashmiri shawl. Let us try to build another view of the Kashmiri shawl from its back face social end and relate that to its present state.

One view that, can be considered at best an apologist one, argues for something akin to the halcyon days of the Kashmiri shawl during the times of the Mughal atelier culture. This view which begins with Ames and finds perhaps its most honest and materialist treatment in Jaffrey and Rehman (and to some degree in Maskiel) points to the end of Mughal rule and the preceding Afghan era which upset the class realities and social relations of production involved in the making of the Kashmiri shawl. Yet the premise of the prosaic, innocuous and relatively comparatively non-commercial and egalitarian craft economy of the high Mughal era is being called out to be romantic exaggerations or even fictions by recent scholarship. Interestingly enough, even after following in Irwin and Ames stead and arguing the apologist stance though in more ambivalent terms, Jaffrey and Rehman along with Zutshi and Maskiel concede that the Mughal premise may be uncertain at least and exaggerated at best.

We can build our alternative and back-face view of the shawl from the little that we know for sure regarding the textile industry and its social relations which the newly formed Kashmiri shawl industry of $15^{\text {th }}$ century that found and made its base and created its own socio economic conditions. The atelier culture of Muslim courts in India were running state sponsored textile workshops that functioned solely for the production of luxury textile goods for the royal house and other royalty plus nobility by extension. Yet the earliest foundational examples out of which the much cited and praised Mughal patron ship evolved, were mutations of a slave based economy. The best example of this is Feroz Shah Tuglaq's (mid- $13^{\text {th }}$ century) decision to create a textile industry attached to his court by turning 12,000 slaves into artisans. This also helps explain why after more than four centuries and despite weavers being the labour group involved in the most lucrative and prestigious craft industry of the Indo-Persian world they remained below the poverty line amongst the lowest socio-economic tier. Let us summarize what we know about the wider social reality of the Kashmiri shawl industry.

We know that several times during the Kashmiri shawl pre- $20^{\text {th }}$ century history, at the peak of its glory as a craft and economy, weavers tried to escape their conditions either through migration to better labour markets or attempting migration with fabricated identities so they would not be sent back to Sri Nagar or be made to weave Kashmiri shawl. We even have accounts accredited by Rehman \& Jaffery and Ames of weaver's cutting off their thumbs as a last desperate attempt to make themselves incapable of weaving, thus making themselves irrelevant to the Kashmiri shawl industry in Kashmir. We also know with considerable detail that for the most part of the five centuries which make up the history of the Kashmiri shawl right up till partition, the weavers were tied to a system of debt-driven labour which practically enslaved entire families to the extent that 12-16 work hour days only ensured that they didn't starve. We also know that for intermittent decades during Afghan, Sikh and early Dogra rule, on and off, weavers were actually only paid in the form of rice that had to be bought from the workshop owner or taxation office.

\section{Conclusion}

From the above, we can conclude that cultural landscapes are dynamic and complex, and need to be understood in dimensions of time as well as space. The axial model presented in this article takes into account the demarcation of cultural zones along time and space as well as in terms of economic and class hierarchy and explains how this is relevant to discourse of appropriation. The concept of appropriation as built in public perception and presented in scholarship has been reviewed and placed in context of historical, cultural and economic realities. Kashmiri shawl has been used as an example due to its suitability as a material culture object with longevity and existing place in discourse on appropriation and authenticity. Returning to our original 
question, the paper has presented the general argument that we can only evolve our ideas regarding the ethics of culture and cultural movement as much as we are invested in understanding the cultural landscape, which has a dynamic and dialectical relationship with the former. Our understanding of the landscape changes our ideas of what is ours and why. It determines how we act as cultural agents, the results of which alter the cultural landscape for us and future generations.

\section{References}

Sanjeev, S., 2008. Indian Renaissance: The: India's Rise After A Thousand Years Of Decline. In: s.l.:World Scientific.

Abu'l Fazl, A. i. M., 1977. Ain-al-Akbari. New Delhi: Asiatic Society of Bengal.

Alkazi, F., 2014. Srinagar: An Architectural Legacy. New Delhi: Roli Books Private Limited.

Ames, F., 1988. The Kashmiri Shawl. s.l.:Antique Collectors Club Ltd..

Anon., 2006. Journal of the Bombay Natural History Society, Volume 103.

Ashai, H. M. S., 1887. Tracts on the Art of Shawl Weaving. Lahore, Kohinoor Press.

Bakshi, S. R., 1997. Kashmir: History and People. s.1.:Sarupa and Sons.

Barnes, R., Crill, R. \& Cohen, S., 2002. Trade, Temple \& Court: Indian Textiles from the Tapi Collection. s.l.:India Book House.

Bernier, F., 2011. Travels in the Mogul Empire. s.1.:Cambridge University Press.

Bier, C. \& Dusenbery, M. M., 2004. Flower, Dragons and Pines: Asian Textiles in the Spencer Museum of Art. s.1.:Hudson Hills

Dhamija, J., 2004. Asian Embroidery. In: s.l.:Abhinav Publications and Crafts Council of India, p. 250.

Fisher, M. H., 2007. Visions of Mughal India: An Anthology of European Travel Writing. s.1.:I.B.Tauris.

Hasan, M., 1959. Kashmir Under the Sultans. In: Delhi : Aakar Books.

Irwin, J., 1973. The Kashmiri Shawl. Victoria Albert Museum Monographs, Issue 29.

Jhala, A. D., 2016. Royal Patronage, Power and Aesthetics in Princely India. New York: Routledge.

Koul, A., 1915. The Kashmiri Shawl Trade. East and West, January, 14(159), pp. 28-42.

Margolena, L. A., 1974. Mohair Histogenesis, Maturation, and Shedding in the Angora Goat. s.1.:Agricultural Research Service, U.S. Department of Agriculture.

Maxwell, R., 2012. Textiles of Southeast Asia: Trade, Tradition and Transformation. In: s.l.:Tuttle Publishing, p. 214.

Rehman, S. \& Jafri, N., 2006. The Kashmiri Shawl: Jamawar to Paisley. s.1.:Mapin Publishing.

Rizvi, J., 2009. Pashmina: The Kashmiri Shawl and Beyond. s.1.:Antique Collectors Club Limited.

Shahabuddin, I., 2008. Medieval India: Essays in Medieval Indian history and Culture. s.1., University of Michigan.

Spengen, W. v., 2010. Tibet Border Worlds. 1st ed. s.1.:Routledge. 